\title{
MICROMORFOMETRIA DE AGREGADOS DO SOLO SOB DIFERENTES SISTEMAS DE CULTIVO DE ARROZ ${ }^{1}$
}

\author{
Cassiano Cremon ${ }^{2}$, Dario $\mathrm{Sacco}^{3}$, Carlo Grignani ${ }^{3}$, Edgard Jardim Rosa Júnior ${ }^{4}$, Nilbe Carla Mapeli²
}

\section{ABSTRACT \\ MICROMORPHOMETRY OF SOIL AGGREGATES UNDER DIFFERENT RICE CROPS MANAGEMENT SYSTEMS}

For a long time, people have tried fo find an index to qualify the soil structure and, for this purpose, the study of soil aggregates digital images can be a promising procedure. The aim of this study was to characterize micromorphometrically aggregates of a typical Dystrudept soil under the influence of different rice crops management systems. The cultivation systems used were: conventional system with sowing in flooded area, sowing in upland area, and crop rotation with maize and rice, in a triennial cycle. Aggregates were collected at 0-0.20 m depths, being used those retained at diameters of $9.52-4.76 \mathrm{~mm}$ and $4.76-2.00 \mathrm{~mm}$, with a standard set of sieves. The aggregates analyses were carried out with the aid of digital images from a scanner (300 dpi) over a total of 100 aggregates disposed over a tray with uneven holes. The images were subsequently analyzed by using the Quantporo program and the aggregates features evaluated were: area, perimeter, roughness, and aspect. Data obtained from soil aggregates micromorphometric analyses were submitted to the frequencies distribution analyses, Chi-square test, and Spearman's nonparametric correlation test. According to the main micromorphometric features of smaller size aggregates $(2.00-4.76 \mathrm{~mm})$, it was possible to conclude that, under the conventional system, aggregates were predominantly smaller, roundish, and smoother.

KEY-WORDS: Digital images; rice crops; soil physics; Inceptisol.

\section{INTRODUÇÃO}

A busca por alternativas de manejo mais sustentáveis/racionais de solos sob arroz irrigado tem sido foco de discussões no cenário mundial, sendo os avanços direcionados a sistemas de manejo que permitam o uso intensivo do solo, sem causar degradação (Gomes et al. 1992, Silveira Neto et al. 2006).

\section{RESUMO}

Há tempos busca-se um índice para qualificar a estrutura do solo e, nesse sentido, o estudo de imagens digitais de agregados do solo pode ser um caminho promissor. O presente trabalho teve por objetivo caracterizar, micromorfometricamente, os agregados de um Cambissolo Háplico Tb distrófico típico sob a influência de diferentes sistemas de manejo na cultura do arroz. Os sistemas de cultivo foram: convencional com semeadura na água, semeadura realizada em sequeiro e rotacionado com milho e arroz em um ciclo trienal. Os agregados foram coletados nas profundidades de $0-0,20 \mathrm{~m}$, sendo utilizados aqueles retidos no intervalo de diâmetro de 9,52-4,76 mm e 4,76-2,00 mm, com um jogo de peneiras padrão. As análises dos agregados foram realizadas por meio de imagens digitais obtidas via scanner (300 dpi) sobre um total de 100 agregados dispostos em um tabuleiro de furos desencontrados. As imagens foram, posteriormente, analisadas com o programa Quantporo e as características dos agregados avaliadas foram: área, perímetro, rugosidade e aspecto. Os dados obtidos das análises micromorfométricas dos agregados do solo foram submetidos a análise de distribuição de frequências, teste de Qui-quadrado e testes de correlação não paramétrica de Spearman. Com base nas principais características micromorfométricas dos agregados menores (2,00-4,76 mm), concluiu-se que, no tratamento convencional, os agregados foram preponderantemente menores, mais arredondados e mais lisos.

PALAVRAS-CHAVE: Imagens digitais; orizicultura; física do solo; Cambissolo.

O cultivo de arroz pode modificar os atributos físicos do solo, devido à utilização de implementos que revolvem continuamente o sistema solo e de práticas, como a terraplanagem, que atuam sobre as camadas superficiais do mesmo.

Neste sentido, a avaliação do sistema poroso do solo é muito importante nas investigações sobre armazenamento e movimento de gases e água, no

1. Trabalho recebido em ago./2009 e aceito para publicação em ago./2011 (nº registro: PAT 7016/ DOI: 10.5216/pat.v41i3.7016).

2. Universidade do Estado do Mato Grosso, Departamento de Agronomia, Cáceres, MT, Brasil.

E-mails: cassiano.cremon@unemat.br,ncmapeli@hotmail.com.

3. Università Degli Studi di Torino, Dipartimento di Agronomia, Torino, PI, Itália.

E-mails: dario.sacco@unito.it, carlo.grignani@unito.it.

4. Universidade Federal da Grande Dourados, Departamento de Agronomia, Dourados, MS, Brasil. E-mail: jjr.jr@ufgd.edu.br. 
estudo de desenvolvimento de raízes de plantas, nos problemas referentes a infiltração e retenção de calor e nas investigações da resistência dos solos à penetração (Silveira et al. 1999). A dinâmica da água, bem como sua disponibilidade, tem sido citada, por muitos autores, como indicador da qualidade física dos solos. Lal (1976) já considerava que os atributos físicos do solo são os principais limitantes no processo de produção agrícola.

No trabalho de construção do conhecimento qualitativo acerca da estrutura de um solo, surgem os estudos das análises digitais de agregados, caracterizando-os segundo suas formas geométricas, por meio de índices e medidas, técnica, esta, conhecida como micromorfometria (Barros et al. 2000, Schaefer et al. 2001).

O desenvolvimento de tecnologias de obtenção, processamento e quantificação de imagens baseadas no uso de microcomputadores e de seus periféricos, segundo Viana (2001), permite que as etapas lentas do processo de análise de imagens em geral, como, por exemplo, as de agregados do solo, sejam efetuadas de forma rápida e automática. Da mesma maneira, Conway \& Jenkins (1983), avaliando a micromorfologia do solo, por meio da análise de imagens via microcomputadores, enfatizaram o baixo custo e a compatibilidade com os recursos da maioria dos usuários, além da facilidade de uso.

As características morfométricas há tempos são utilizadas em estudos de sedimentologia. A forma e o arredondamento dos grãos de areia e dos seixos têm sido usados para decifrar histórias de depósitos sedimentares (Suguio 1973). Para este mesmo autor, uma descrição da forma geométrica de partículas envolve, normalmente, vários conceitos relacionados. De um lado há os fatores de forma, que dependem dos comprimentos dos eixos principais perpendiculares entre si, e, de outro, a angularidade ou arredondamento das partículas. A forma ou as relações de comprimento dos eixos controlam, parcialmente, o comportamento dos seixos, durante o transporte e a deposição, enquanto o arredondamento ou rugosidade são decorrentes da distância e rigor do transporte.

É importante, neste sentido, que se tenha um processo simples e objetivo, que permita expressar, numericamente, a forma e tamanho das estruturas, não somente para fins descritivos, mas, também, para execução de estudos quantitativos de vários fatores envolvidos na evolução, até a forma final da partícula ou do fragmento. A forma e distribuição dos poros, em diferentes sistemas de preparo de solo, por meio de imagens em preto e branco, têm sido estudadas por diferentes autores, tais como Schaefer et al. (2001), Olszevski et al. (2004) e Cremon et al. (2009). Atualmente, surge uma nova linha de pesquisa, que visa a analisar a transformação e reversibilidade da estrutura do solo por quantificação da sua morfologia, utilizando-se a análise de imagens obtidas por câmera de vídeo acoplada a microscópio.

Para Brewer (1976), a estrutura representa a própria constituição física do solo, expressa pelo tamanho, forma e distribuição, ou pelo arranjo dos espaços vazios e das partículas sólidas do solo, sejam elas primárias ou secundárias. Fernandes (1982), Dadalto et al. (1989) e Rosa Júnior et al. (2006) concluíram que os agregados mostram diferenças, quanto ao tamanho, forma, estabilidade e adesão entre si, e que alterações nas condições naturais do solo, por sistemas de manejo, podem alterar o tamanho, distribuição e estabilidade destes agregados.

Considerando-se o acima exposto, realizou-se este trabalho com o objetivo de caracterizar e comparar, micromorfometricamente, os agregados de um Cambissolo, sob a influência de diferentes sistemas de manejo da cultura do arroz, no norte da Itália.

\section{MATERIAL E MÉTODOS}

O trabalho foi conduzido no Instituto Galileu Ferraris, no município de Vercelli, região norte da Itália, no ano de 2005, em Cambissolo háplico Tb distrófico típico. Os tabuleiros mediam $100 \mathrm{~m}$ de comprimento por $25 \mathrm{~m}$ de largura e foram isolados hidraulicamente entre si, por meio de barreiras físicas levantadas com solo, tendo por objetivo analisar e monitorar, separadamente, cada sistema de cultivo, sem que ocorressem efeitos de diluição ou acúmulo, devido à transferência de material de um tabuleiro a outro.

Os tratamentos foram os seguintes: $\mathrm{CON}$ (sistema convencional da região, com manejo da palhada incorporada, aração realizada em outubro, semeadura em submersão e ausência de rotação de culturas), SEQ (sistema com manejo da palhada incorporada, aração realizada na primavera, semeadura em sequeiro e ausência de rotação de culturas) e ROT (sistema com manejo da palhada incorporada, aração realizada na primavera, sem irrigação e rotação com milho a cada três anos). 
O histórico de cultivo, no tabuleiro ROT, ao longo dos anos, foi: 2002 (milho), 2003 (arroz), 2004 (arroz) e 2005 (milho). Paralelamente, nos tabuleiros CON e SEQ, aconteciam monocultivos da cultura do arroz com seu respectivo sistema de cultivo.

Em março de 2003, realizou-se o primeiro ano de caracterização do solo, sendo feita a caracterização química e granulométrica, à profundidade de $0-25 \mathrm{~cm}$ (Tabela 1).

A amostragem do material destinado à análise química e micromorfométrica deu-se no mês de março de 2005, quando não havia nenhuma cultura a campo. As análises químicas foram realizadas segundo metodologia de rotina (SIA 2000). Os agregados foram amostrados à profundidade de 0-20 cm, sendo coletados aqueles retidos no intervalo de 2,00-4,76 mm e 4,76-9,52 mm de diâmetro, por meio de um jogo de peneiras padrão (Cremon et al. 2009). Foram abertas trincheiras com dimensões aproximadas de $40 \mathrm{~cm}$ x $40 \mathrm{~cm}$ x $40 \mathrm{~cm}$, nos três pontos (alto, médio e baixo) de cada tabuleiro. A amostragem foi feita com pá reta, sendo o solo destorroado manualmente no campo, aplicando-se leve pressão, para causar o mínimo de mudanças em sua estrutura original. Os agregados foram separados mediante peneiramento a campo, via movimentos leves, e com quantidades pré-estabelecidas (movimentos de vai e vem, por dez vezes), seguindo-se a metodologia proposta por Cremon et al. (2009). Os agregados foram acondicionados em frascos de plás-

Tabela 1. Caracterização química e granulométrica do solo, à profundidade de $0,25 \mathrm{~m}$, sob diferentes sistemas de cultivo de arroz (Vercelli, Itália, 2005).

\begin{tabular}{|c|c|c|c|c|}
\hline \multirow{2}{*}{\multicolumn{2}{|c|}{ Atributos }} & \multicolumn{3}{|c|}{ Manejo } \\
\hline & & $\mathrm{CON}$ & SEQ & ROT \\
\hline Areia & $\mathrm{g} \mathrm{kg}^{-1}$ & 465 & 348 & 371 \\
\hline Silte & $\mathrm{g} \mathrm{kg}^{-1}$ & 412 & 547 & 529 \\
\hline Argila & $\mathrm{g} \mathrm{kg}^{-1}$ & 123 & 105 & 100 \\
\hline $\mathrm{pH}$ & água & 6,7 & 6,4 & 6,7 \\
\hline C. org. & dag $\mathrm{kg}^{-1}$ & 0,7 & 1,1 & 1,2 \\
\hline $\mathrm{N}$ Total & $\mathrm{g} \mathrm{kg}^{-1}$ & 0,59 & 0,87 & 1,18 \\
\hline $\mathrm{C} / \mathrm{N}$ & - & 10,5 & 12,5 & 10,5 \\
\hline CTC & $\mathrm{cmol}_{\mathrm{c}} \mathrm{cm}^{-3}$ & 11,2 & 11,2 & 12,5 \\
\hline K & $\mathrm{mg} \mathrm{dm}^{-3}$ & 45,6 & 41,6 & 40 \\
\hline $\mathrm{P}$ & $\mathrm{mg} \mathrm{dm}^{-3}$ & 26,5 & 32,3 & 40 \\
\hline
\end{tabular}

CON - sistema convencional da região. SEQ - sistema com manejo da palhada incorporada, aração realizada na primavera, semeadura em sequeiro e ausência de rotação de culturas. ROT - sistema com manejo da palhada incorporada, aração realizada na primavera, sem irrigação e rotação com milho a cada três anos. CTC - capacidade de troca catiônica. tico liso e, posteriormente, levados para análise em laboratório. As amostras foram secas ao ar, antes de serem submetidas a qualquer tratamento ou análise.

$\mathrm{O}$ estudo deu-se com a obtenção de imagens dos agregados, utilizando-se um scanner (HP 6100C, com capacidade de resolução ótica de 1.200 dpi), e posterior processamento destas imagens, pelo programa computacional Quantporo. Uma amostra de 100 agregados de cada tabuleiro foi distribuída sobre o scanner, sendo os mesmos separados mediante utilização de uma plataforma projetada com furos desencontrados. Para o estudo em questão, optou-se por uma resolução de 300 dpi, para obtenção das imagens. Utilizou-se o sistema de cores RGB na preparação das imagens, para posterior análise. As imagens foram submetidas ao filtro de mediana, que opera substituindo os valores de cada pixel pelo valor da mediana dos pixels da vizinhança. Seu efeito principal consiste na redução de pixels isolados, grande parte destes ruídos ou artefatos, que ocasionam distorções, principalmente nas medidas de perímetro. Todas as imagens foram convertidas em sua forma binária, por meio do comando threshold. Após o processamento pelo Quantporo, as medidas foram disponibilizadas em unidades do Sistema Internacional, sendo elas: 1. Área $\left(\mathrm{cm}^{2}\right)$ : medida com o número de pixels no polígono; 2. Perímetro (cm): comprimento da projeção do limite exterior do agregado; 3 . Aspecto: fornece o resultado entre 0 e 1 e, quanto maior o valor, maior o grau de arredondamento, sendo calculado a partir da fórmula: (4 x $\pi$ x área)/perímetro ${ }^{2} ; 4$. Rugosidade: expressa as estrias do agregado, sendo que, quanto mais liso, mais próximo de 1 .

Os dados obtidos das análises micromorfométricas dos agregados do solo foram submetidos ao teste de distribuição de frequências, sendo as classes definidas segundo a fórmula de Stunges, $\mathrm{K}=1+3,22 * \log \mathrm{n}$, sendo $K$ o número de classes e $n$ o número total de indivíduos da população. As distribuições foram avaliadas segundo o teste de Qui-quadrado, teste de mediana e correlação não paramétrica de Spearman.

\section{RESULTADOS E DISCUSSÃO}

Com base nas análises de distribuição de frequência dos agregados, em função da área dos mesmos, constataram-se seis classes distintas (Figura 1). As dimensões dos agregados variaram 
de maiores que $0,15 \mathrm{~cm}^{2}$ a menores que $0,55 \mathrm{~cm}^{2}$, dentro de uma faixa de peneiramento entre $4,76 \mathrm{~mm}$ e 9,52 $\mathrm{mm}$ de diâmetro de malha, e maiores que $0,07 \mathrm{~cm}^{2}$ a menores que $0,15 \mathrm{~cm}^{2}$, dentro de uma faixa de peneiramento entre $2,00 \mathrm{~mm}$ e $4,76 \mathrm{~mm}$ de diâmetro de malha (Figura 1). Foi aplicado o teste de Qui-quadrado para as diferentes distribuições de frequências e constatou-se que não existem diferenças significativas para a variável área, na avaliação dos agregados de maior diâmetro, significando que as tendências de aparecimento de classes de agregados são iguais em todos os tratamentos (Figura 1a).

Já na análise dos agregados de menor diâmetro, constatou-se diferença significativa (1\%), pelo teste de Qui-quadrado (Figura 1b). O tratamento SEQ foi o que proporcionou maior frequência de agregados menores, concentrando a maior parte dos mesmos na faixa de $0,07-0,09 \mathrm{~cm}^{2}$. O tratamento CON também seguiu uma tendência de apresentar agregados de tamanhos menores, com maior concentração na classe de $0,09-0,11 \mathrm{~cm}^{2}$ de área. Já o sistema ROT foi o que se diferenciou dos demais, por proporcionar tendência de agregação, sendo que a maior frequência dos agregados foi na faixa de $0,11 \mathrm{~cm}^{2} \mathrm{a}>0,15 \mathrm{~cm}^{2}$.

Sendo assim, verificou-se que os sistemas que mantiveram água durante todos os anos de cultivo (2002 a 2005) propiciaram incrementos no número de agregados menores. Isto pode estar vinculado ao fato de este sistema apresentar menor teor de matéria orgânica (M.O.) e carbono orgânico (C.O.), como se segue: tabuleiros CON, SEQ e ROT = M.O. $\left(\right.$ dag kg$\left.^{-1}\right)=1,36 ; 1,67 ;$ e 2,04, respectivamente. Segundo Roscoe \& Machado (2002), sistemas onde o fluxo de carbono é mais intenso tendem a apresentar atividade biológica maior e, consequentemente, um processo de ordenação biológica que favorece a estruturação do solo, sendo, provavelmente, o que ocorreu no sistema ROT.

Outra inferência que se pode fazer é à respeito do efeito da água como agente desagregador na estrutura do solo, principalmente pela presença constante de uma lâmina d'água sobre o solo. Este efeito pode estar associado à necessidade de realização de práticas agrícolas como aração, gradagem e tratos culturais, em que o implemento transita na área com o solo úmido, incrementando possíveis efeitos de compactação e desagregação (Silveira Neto et al. 2006, Magalhães et al. 2009).

Estes resultados corroboram os encontrados por Cremon et al. (2009) e Olszevski et al. (2004), que, analisando a micromorfometria de agregados de um Latossolo de textura argilosa, comparando-se diferentes sistemas de manejo (plantio direto e convencional), constataram que as diferenças de área dos agregados se devem, em parte, ao aporte de material vegetal no solo e ao não revolvimento do mesmo. Resultados semelhantes

\subsection{6 a $9,52 \mathrm{~mm}$}

a

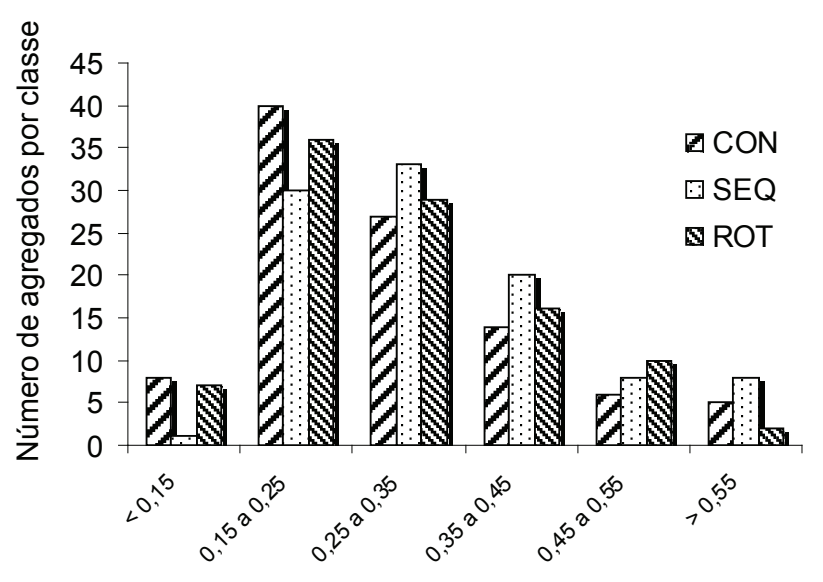

Área dos agregados em $\mathrm{cm}^{2}$

\section{2,00 a $4,76 \mathrm{~mm}$}

b

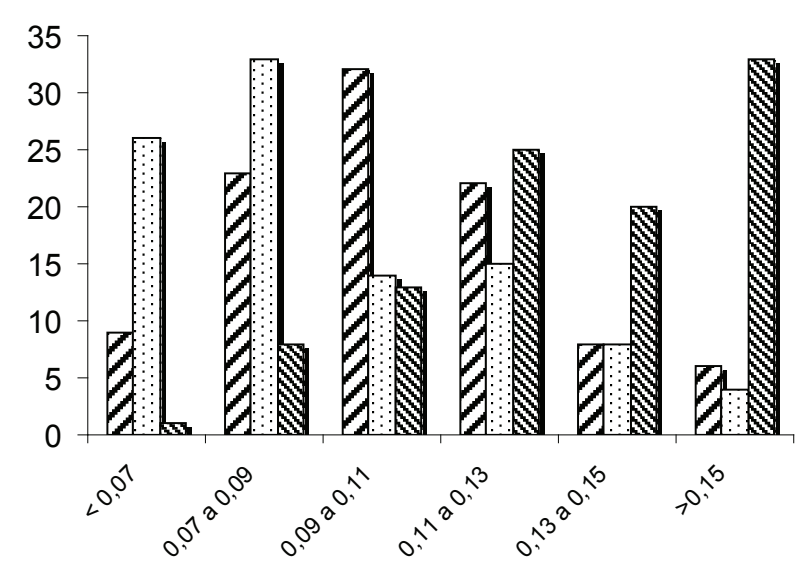

Área dos agregados em $\mathrm{cm}^{2}$

Figura 1. Frequência de agregados nas diferentes classes de tamanho (a e b), sob diferentes sistemas de manejo da cultura do arroz (Vercelli, Itália, 2005). 
foram obtidos por Cremon (2004), que constatou que o aporte de material vegetal de milho, com leguminosas consorciadas, incrementou a área dos agregados, porém, com a ressalva de que estes resultados foram observados para solos tropicais. Os agregados analisados neste trabalho foram os da camada $0-20 \mathrm{~cm}$, porção mais afetada pelas práticas agrícolas e pelos agentes erosivos, mesmo em manejos conservacionistas onde estes efeitos são menos pronunciados. Olszevski et al. (2004), analisando imagens digitais de agregados oriundos de diferentes sistemas de cultivo, ressaltaram que sistemas que se utilizam de grades, arados de discos e/ou aivecas promovem a pulverização dos agregados do solo.

O perímetro é uma característica que expressa o comprimento da borda dos agregados $(\mathrm{cm})$ e tem relação intrínseca com a área dos mesmos, pois, quanto maior o agregado, maior o comprimento da borda. Nas Figuras 2 e 3, pode-se observar a distribuição dos
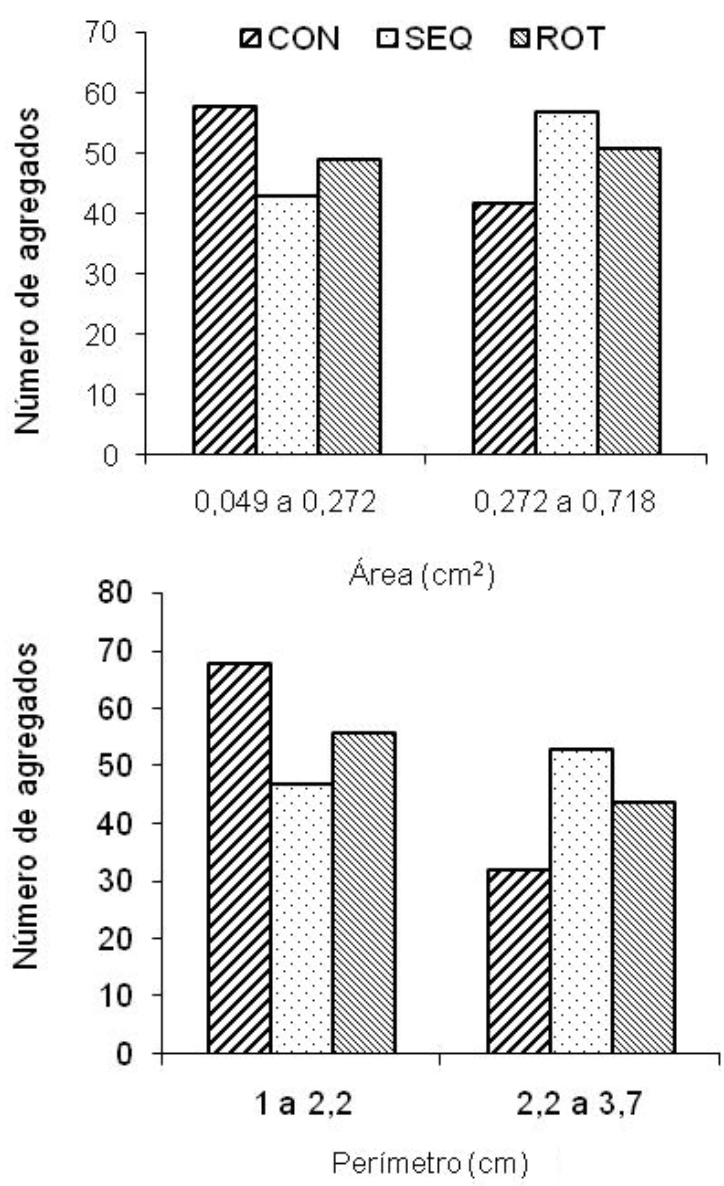

agregados, para cada tratamento, sendo que foram verificadas diferenças significativas $(p<0,01)$, pelo teste de mediana. Nos agregados de maior diâmetro (Figura 2), o tratamento SEQ foi o que apresentou maior frequência de agregados com maior perímetro e o tratamento CON maior frequência de agregados com menor perímetro. Nos grupos de agregados de menor diâmetro (Figura 3), constatou-se que o tratamento ROT foi o que apresentou maior número de agregados com perímetro maior.

Observou-se que, no sistema ROT, há incremento na área dos agregados e maior comprimento do entorno das estrias dos mesmos, característica, esta, que pode estar relacionada à maior resiliência dos agregados ou tendência à agregação. Segundo Olszevski et al. (2004), acredita-se que sistemas de manejo que promovam menor revolvimento do solo devam apresentar maiores valores para a variável perímetro, graças à maior proporção de agregados de tamanho e rugosidade externa maiores.
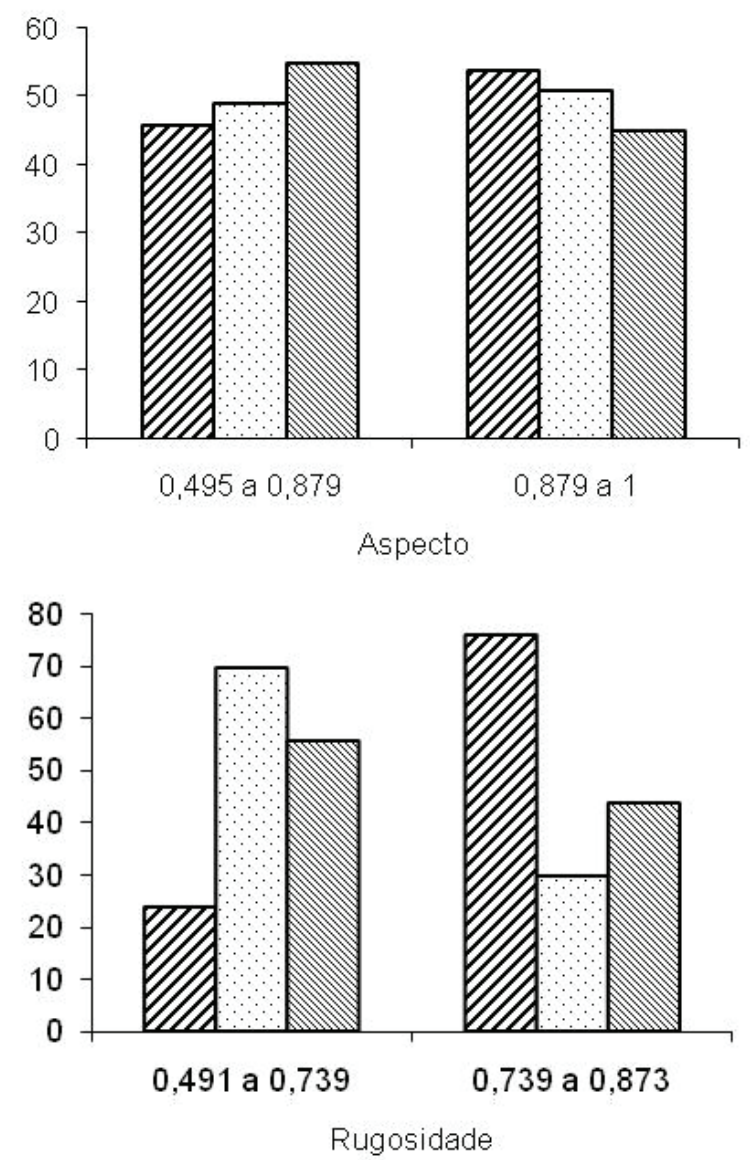

Figura 2. Área, perímetro, rugosidade e aspecto dos agregados, no intervalo 4,76-9,52 mm, separados segundo o teste de mediana, para um Cambissolo sob diferentes sistemas de manejo da cultura do arroz (Vercelli, Itália, 2005). 
Para a característica aspecto, que expressa o grau de arredondamento dos agregados, constatou-se não haver diferenças significativas, pelo teste de mediana, para os agregados grandes (Figura 2). Em todos os sistemas, ocorreu uma tendência ao aparecimento de agregados arredondados, lembrando-se que os índices que variam $0,83-0,90$ são agregados de forma preponderantemente quadrada, tendendo ao arredondamento, ou com vértices arredondados.

Diferentemente dos agregados grandes, os agregados menores apresentaram tendências diferenciadas, para cada sistema de cultivo analisado (Figura 3). O tratamento CON foi o que apresentou maior parte dos agregados perfeitamente redondos e os tratamentos SEQ e ROT apresentaram maiores proporções de agregados preponderantemente quadrados ou alongados. Segundo Olszevski et al. (2004), para o índice de arredondamento, os sistemas de manejo que provocam menor revolvimento do solo devem apresentar menores valores para a variável arredondamento, pois esta é dependente da medida de perímetro. Logo, maiores valores de arredondamento deverão ser encontrados para os agregados provenientes de sistemas de manejo mais agressivos à estrutura, pois estes tenderão a perder a rugosidade da superfície externa, diminuindo, assim, o valor do perímetro.

Com relação à variável rugosidade, o índice 1 indica superfície perfeitamente lisa. Constatou-se que, para os agregados maiores, o tratamento $\mathrm{CON}$ apresentou a grande maioria dos agregados com índice de rugosidade entre 0,73 e 0,87 (Figura 2). Por outro lado, os tratamentos SEQ e ROT apresentaram maior frequência de agregados com maior número de estrias (rugosidade), sendo estas distribuições estatisticamente diferentes $(\mathrm{p}<0,01)$, pelo teste de mediana. No grupo dos agregados de menor diâmetro, esta diferença estatística não foi constatada, sendo que todos os agregados apresentaram a mesma tendência à rugosidade (Figura 3). Análises micromorfométricas têm demonstrado que sistemas de manejo que promovam menor revolvimento do solo
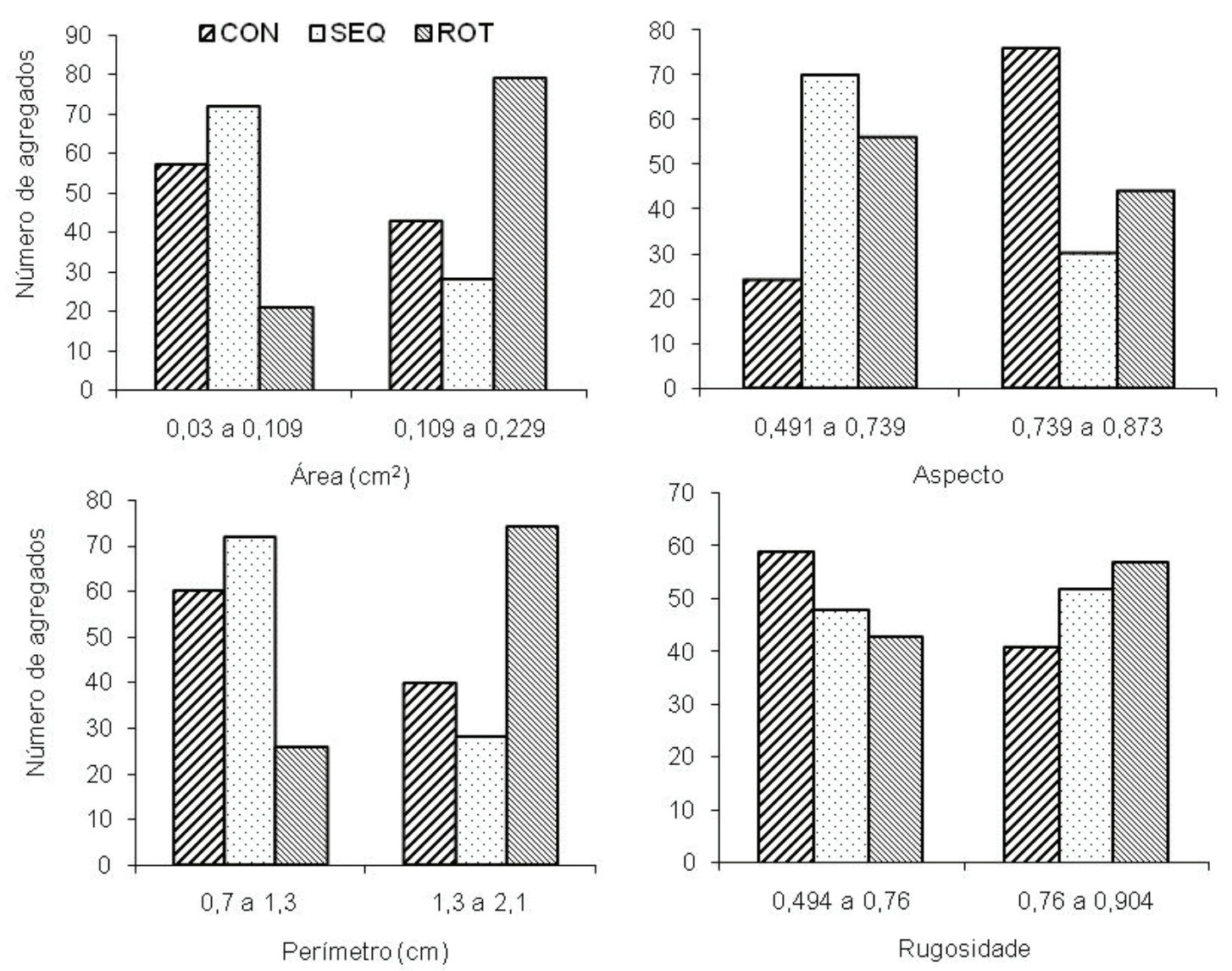

Figura 3. Área, perímetro, rugosidade e aspecto dos agregados, no intervalo 2,00-4,76 mm, separados segundo o teste de mediana, para um Cambissolo sob diferentes sistemas de manejo da cultura do arroz (Vercelli, Itália, 2005). 
devem apresentar maiores valores ou proporções de agregados de tamanho e rugosidade externa maiores. Sendo assim, o aparecimento destas diferenças entre os tratamentos CON, SEQ e ROT, somente nos agregados maiores, pode ser indicativo de degradação em fase inicial, neste caso relacionada à presença de água no solo e à utilização de práticas constantes de revolvimento.

Na Tabela 2, são apresentadas as características dos agregados, separados por grupos de tamanho. Constatou-se que, de maneira significativa, os tratamentos CON e SEQ mostraram, para os agregados maiores, correlação negativa entre área e rugosidade, o que significa que, quanto maior o agregado, mais rugoso este se torna, porém, esta tendência não se mantém nos agregados menores. Quanto à correlação área $\mathrm{x}$ aspecto, percebe-se que o tratamento ROT foi o único que, nos agregados menores, apresentou correlação negativa significativa ( $p<0,01)$, o que implica em dizer que, quanto maior o agregado, maior a tendência da forma quadrada. Para explicar estes resultados, sugere-se, para experimentos futuros, a análise da qualidade da matéria orgânica e de agentes agregantes presentes no solo, para que se possa inferir o efeito das diferentes frações orgânicas presentes no solo e sua relação com a forma dos agregados.

Fazendo-se uma junção das principais características micromorfométricas dos agregados menores (2,00-4,76 mm), é possível inferir que, no tratamento $\mathrm{CON}$, os agregados são preponderantemente menores, mais arredondados e mais lisos. No tratamento SEQ, os agregados são ainda menores que no tratamento $\mathrm{CON}$, porém tendendo a serem mais quadrados e mais rugosos. Já o tratamento ROT foi o que apresentou maior frequência de agregados grandes, faixa de tamanho arredondada e tendência a aumento na rugosidade (Figura 3).

Embora não tenha sido objetivo deste trabalho, pôde-se averiguar que as análises micromorfométricas monstraram-se muito sensíveis na detecção de pequenas variações nos agregados do solo, o que corrobora a conclusão de Olszevski et al. (2004).

Percebe-se que, embora no tratamento ROT tenha sido cultivado arroz no manejo convencional, em 2003 e 2004, a presença do milho, em especial da palhada do milho, no ano de 2002, e o modo com que esta parcela foi manejada, propiciaram a detecção de características de menor impacto na morfologia dos agregados, apresentando-se como sistema de manejo menos impactante à estrutura do solo.

\section{CONCLUSÕES}

1. Agregados de maior diâmetro (4,76-9,52 mm) não apresentaram diferenças de área entre os diversos sistemas de cultivo.

2. O sistema rotacionado foi o que apresentou maior proporção de agregados com área maior para agregados menores $(2,00-4,76 \mathrm{~mm})$.

3. O sistema que mais influenciou na qualidade dos agregados, tornando-os preponderantemente menores, mais redondos e lisos, foi o convencional.

4. O manejo rotacionado foi o menos impactante à estrutura do solo.

Tabela 2. Correlação não paramétrica de Spearman (com 100 repetições) entre as características analisadas dos agregados de um Cambissolo sob diferentes sistemas de manejo da cultura do arroz (Vercelli, Itália, 2005).

\begin{tabular}{|c|c|c|c|c|c|c|c|}
\hline & & \multicolumn{3}{|c|}{$4,76-9,52 \mathrm{~mm}$} & \multicolumn{3}{|c|}{$2,00-4,76 \mathrm{~mm}$} \\
\hline & & Área & Perímetro & Rugosidade & Área & Perímetro & Rugosidade \\
\hline \multirow[t]{3}{*}{$\mathrm{CON}$} & Perímetro & $0,986 * *$ & & & $0,938 * *$ & & \\
\hline & Rugosidade & $-0,201^{*}$ & $-0,322 * *$ & & $0,000^{\mathrm{ns}}$ & $-0,275^{* *}$ & \\
\hline & Aspecto & $0,013^{\text {ns }}$ & $-0,038^{\mathrm{ns}}$ & $0,331 * *$ & $0,054^{\mathrm{ns}}$ & $-0,073^{\text {ns }}$ & $0,418 * *$ \\
\hline \multirow[t]{3}{*}{ SEQ } & Perímetro & $0,964 * *$ & & & $0,956 * *$ & & \\
\hline & Rugosidade & $-0,242 *$ & $-0,467 * *$ & & $0,039^{\mathrm{ns}}$ & $-0,178^{\mathrm{ns}}$ & \\
\hline & Aspecto & $0,111^{\mathrm{ns}}$ & $0,049^{\mathrm{ns}}$ & $0,218^{*}$ & $0,073^{\mathrm{ns}}$ & $0,039^{\text {ns }}$ & $0,389 * *$ \\
\hline \multirow[t]{3}{*}{ ROT } & Perímetro & $0,971 * *$ & & & $0,96 * *$ & & \\
\hline & Rugosidade & $-0,127^{\mathrm{ns}}$ & $-0,329 * *$ & & $-0,134^{\mathrm{ns}}$ & $-0,34 * *$ & \\
\hline & Aspecto & $0,044^{\mathrm{ns}}$ & $0,003^{\mathrm{ns}}$ & $0,226^{*}$ & $-0,223^{*}$ & $-0,259 * *$ & $0,314 * *$ \\
\hline
\end{tabular}

\footnotetext{
* Significativo $(\mathrm{p}<0,05)$.** Significativo $(\mathrm{p}<0,01)$. ns Não significativo. CON - sistema convencional da região. SEQ - sistema com manejo da palhada incorporada, aração realizada na primavera, semeadura em sequeiro e ausência de rotação de culturas. ROT - sistema com manejo da palhada incorporada, aração realizada na
} primavera, sem irrigação e rotação com milho a cada três anos. 


\section{REFERÊNCIAS}

BARROS, E. et al. Role of macrofauna in the transformation and reversibility of soil structure of an Oxisol during forest to pasture conversion. Geoderma, Amsterdam, v. 100, n. 1, p. 193-213, 2000.

BREWER, R. Fabric and mineral analysis of soils. New York: Robert Krieger, 1976.

CONWAY, J.; JENKINS, D. A simple procedure for the quantification of void shapes in soil thin sections. In: BULLOCK, P.; MURPHY, C. P. (Eds.). Soil micromorphology: techniques and applications. Berkhamsted: A. B. Academic, 1983.

CREMON, C. Variação temporal dos atributos de um Latossolo Vermelho, cultivado com leguminosas para adubação verde. 2004.79 f. Dissertação (Mestrado em Solos e Nutrição de Plantas)-Universidade Federal de Viçosa, Viçosa, 2004.

CREMON, C. et al. Análise micromorfométrica de agregados de um Latossolo Vermelho distroférrico sob diferentes sistemas de manejo. Acta Scientiarum, Maringá, v. 31, n. 1, p. 139-146, 2009.

DADALTO, G. G.; COSTA, L. M.; MOURA FILHO, W. Alterações em características físicas de solos cultivados com pastagem. Revista Ceres, Viçosa, v. 36, n. 206, p. 317 329, 1989.

FERNANDES, M. R. Alterações em propriedades de um Latossolo Vermelho-Amarelo distrófico, fase cerrado, decorrentes da modalidade de uso e manejo. 1982. 65 f. Tese (Doutorado em Solos e Nutrição de Plantas)Universidade Federal de Viçosa, Viçosa, 1982.

GOMES, A. S. et al. Solos de várzea: uso e manejo. In: MARCÂNTONIO, G. (Coord.). Solos e irrigação. Porto Alegre: Ed. da UFRGS, 1992. p. 64-79.

LAL, R. Soil erosion on Alfisols in Western Nigeria: effects of rainfall characteristics. Geoderma, Amsterdam, v. 16, n. 15 , p. $389-401,1976$.

MAGALHÃES, E. N. et al. Recuperação estrutural e produção de capim-tifton 85 em um Argissolo VermelhoAmarelo compactado. Ciência Animal Brasileira, Goiânia, v. 10, n. 1, p. 68-76, 2009.
OLSZEVSKI, N. et al. Morfologia de agregados do solo avaliada por meio de análise de imagens. Revista Brasileira de Ciência do Solo, Viçosa, v. 28, n. 5, p. 901909, 2004.

ROSA JÚNIOR, E. J. et al. Calcário e gesso como condicionantes físico e químico de um solo de Cerrado sob três sistemas de manejo. Pesquisa Agropecuária Tropical, Goiânia, v. 36, n. 1, p. 37-44, 2006.

ROSCOE, R.; MACHADO, P. L. O. A. Fracionamento fisico do solo em estudos de matéria orgânica. Dourados: Embrapa Agropecuária Oeste, 2002.

SCHAEFER, C. E. G. R. et al. Características da porosidade de um Argissolo Vermelho-Amarelo submetido a diferentes sistemas de preparo do solo. Revista Brasileira de Ciência do Solo, Viçosa, v. 25, n. 3, p. 775-779, 2001.

SILVEIRA, P. M. et al. Alterações na densidade e na macroporosidade de um Latossolo Vermelho-Escuro causadas pelo sistema de preparo do solo. Pesquisa Agropecuária Tropical, Goiânia, v. 29, n. 2, p. 145-149, 1999.

SILVEIRA NETO, A. N. et al. Efeitos de manejo e rotação de culturas em atributos físicos do solo. Pesquisa Agropecuária Tropical, Goiânia, v. 36, n. 1, p. 29-35, 2006.

SOCIETÀ ITALIANA DI AGRONOMIA (SIA). Mètodo italiano di anàlise del suolo: analisi chimice ed fisici del suolo. Milano: Società Italiana di Agronomia, 2000.

SUGUIO, K. Introdução à sedimentologia. São Paulo: Edgard Blucher, 1973.

VIANA, J. H. M. Análise de imagens micropedológicas com utilização do programa Quantporo e sua aplicação ao estudo de umedecimento e secagem em amostras de latossolos. 2001. 70 f. Dissertação (Mestrado em Solos e Nutrição de Plantas)-Universidade Federal de Viçosa, Viçosa, 2001. 